Article

\title{
Capacitively Coupled Plasma Discharge of Ionic Liquid Solutions to Synthesize Carbon Dots as Fluorescent Sensors
}

\author{
Ching-Bin Ke ${ }^{1}$, Te-Ling $\mathrm{Lu}^{2}$ and Jian-Lian Chen ${ }^{2, *}$ \\ 1 Department of Beauty and Health Care, Min-Hwei Junior College of Health Care Management, No. 1116, \\ Sec. 2, Zhongshan E. Rd., Tainan 73658, Taiwan; cbke@mail.mhchcm.edu.tw \\ 2 School of Pharmacy, China Medical University, No. 91 Hsueh-Shih Road, Taichung 40402, Taiwan; \\ lutl@mail.cmu.edu.tw \\ * Correspondance: cjl@mail.cmu.edu.tw; Tel.: +886-4-22-053-366
}

Received: 25 April 2018; Accepted: 23 May 2018; Published: 26 May 2018

\begin{abstract}
Oxygen and nitrogen capacitively coupled plasma (CCP) was used to irradiate mixtures of aliphatic acids in high boiling point solvents to synthesize fluorescent carbon dots (C-dots). With a high fluorescence intensity, the $\mathrm{C}$-dots obtained from the $\mathrm{O}_{2} / \mathrm{CCP}$ radiation of a 1-ethyl-3-methylimidazolium dicyanamide ionic liquid solution of citric acid were characterized with an average diameter of $8.6 \mathrm{~nm}(\sigma=1.1 \mathrm{~nm})$, nitrogen and oxygen bonding functionalities, excitation-independent emissions, and upconversion fluorescence. Through dialysis of the CCP-treated C-dots, two emissive surface states corresponding to their respective functionalities and emissions were identified. The fluorescence spectrum of the CCP-treated C-dots was different from that of the microwave irradiation and possessed higher intensity than that of hydrothermal pyrolysis. By evaluation of the fluorescence quenching effect on flavonoids and metal ions, the CCP-treated C-dots showed a high selectivity for quercetin and sensitivity to $\mathrm{Hg}^{2+}$. Based on the Perrin model, a calibration curve $\left(R^{2}=0.9992\right)$ was established for quercetin ranging from $2.4 \mu \mathrm{M}$ to $119 \mu \mathrm{M}$ with an LOD (limit of detection) $=0.5 \mu \mathrm{M}$. The quercetin in the ethanol extract of the sun-dried peel of Citrus reticulata $\mathrm{cv}$. Chachiensis was determined by a standard addition method to be $4.20 \pm 0.15 \mathrm{mg} / \mathrm{g}$ with a matrix effect of $8.16 \%$.
\end{abstract}

Keywords: capacitively coupled plasma; carbon dots; ionic liquid; mercury ion; quercetin; upconversion

\section{Introduction}

Carbon dots (C-dots) have readily acquired predominance over commercial dyes and conventional semiconductor quantum dots in a wide variety of analytical and biomedical applications, including (bio)chemical sensing, photocatalysis, electrochemiluminescence, photoelectrochemical sensing, bioimaging, and drug delivery, because of their tunable photoluminescence, fine resistance to photobleaching, excellent water solubility, good biocompatibility, and ease of synthesis [1-4]. Based on the chosen carbonaceous precursors, the approaches to synthesize C-dots are divided into top-down and bottom-up routes [3-6]. The former involves cleaving or breaking down relatively macroscopic carbonaceous materials, such as carbon nanotubes, graphite columns, and graphene powder, via acidic and electrochemical oxidation, arc-discharge, and laser ablation. The latter is realized through carbonization of small organic molecules via solvothermal and hydrothermal pyrolysis, microwave and ultrasonic irradiation, and plasma treatment. The low requirement for carbon molecules in the bottom-up route is advantageous for obtaining C-dots with desirable morphological, functional, and spectral properties. 
Due to equipment availability, plasma treatment is less reported than other approaches, especially compared to the mainly utilized microwave and hydrothermal syntheses. However, the ability to control the nanoscale localization of energy and matter delivered from bulk plasmas to form nano-solids is capable of unique self-organized processes [7]. In 2010, C-dots were first generated by the reaction of benzene with atmosphere helium cavitation gas in a submerged-arc plasma reactor [8]. Another plasma-liquid system used argon atmospheric-pressure microplasma as gaseous electrodes to purge an aqueous solution containing citric acid and ethylenediamine to produce C-dots [9]. Without the need for a well-designed reactor, the plasma-gas system can use gaseous and solid organic precursors. Methane, hydrogen, and nitrogen were used as the reactive gases in a plasma-enhanced hot filament chemical vapor deposition of carbon nanofilms and nanodots [10]. Ethylene gas was introduced continuously along with the thermal argon plasma jet at sound velocity to produce graphene quantum dots [11,12]. Also, solid egg white, yolk, acrylamide, and ashes of plant leaves were irradiated by air atmospheric-pressure dielectric barrier discharge plasmas to generate C-dots [13-15]. No liquid precursors have been irradiated in a plasma-gas system to obtain C-dots.

In this study, aliphatic acids dispersed in viscous media, ionic liquids and high b.p. solvents, were irradiated with capacitively coupled plasma (CCP) between regular plate electrodes in a low-pressure chamber, in presence of oxygen; to obtain C-dots. Due to its high fluorescence intensity, the C-dots synthesized via $\mathrm{O}_{2} / \mathrm{CCP}$ treatment of 1-ethyl-3-methylimidazolium dicyanamide solution of citric acid were further characterized to determine the physical dimensions, crystallinity, functionality, and spectral properties of the C-dots. A possible fluorescence mechanism was proposed. After comparison with hydrothermal and microwave treatments, the $\mathrm{O}_{2} / \mathrm{CCP}$-treated C-dots were applied to detect metal ions and flavonoids.

\section{Materials and Methods}

\subsection{Materials and Chemicals}

Citric acid was purchased from Acros (Thermo Fisher Scientific, Geel, Belgium). Malic acid, ethylene glycol, 1,4-butanediol, and poly(ethylene imide) (PEI, branched, $\mathrm{Mn}=600, \mathrm{Mw}=800$ ) were from Aldrich (Milwaukee, WI, USA). Poly(ethylene glycol) (PEG, Mn =1000) was purchased from Alfa Aesar (Ward Hill, MA, USA). Adipic acid, succinic acid, and glycerol were from Showa (Tokyo, Japan). Ionic liquids were purchased from Aldrich (1-ethyl-3-methylimidazolium dicyanamide, [EMIM]N(CN $)_{2} ;$ 1-ethyl-3-methylimidazolium tetrachloroaluminate, [EMIM] $\mathrm{AlCl}_{4}$; 1-methyl-3-octylimidazolium chloride, [MOIM]Cl); and trihexyltetradecylphosphonium dicyanamide, $\left.[\mathrm{P} 6,6,6,14] \mathrm{N}(\mathrm{CN})_{2}\right)$ and Alfa Aesar (1-butyl-3-methylimidazolium tetrafluoroborate, [BMIM]BF 1-butyl-3-methylimidazolium chloride, [BMIM]Cl; and 1-butyl-3-methylimidazolium bromide, [BMIM]Br). Nine flavonoids (5-methoxyflavone (Met), hesperidin (Hpd), naringin (Nag), catechin (Cat), epicatechin (Epi), hesperetin (Hpt), daidzein (Dai), naringenin (Nar), and quercetin (Que)) were from Aldrich. All metal and phosphate salts were of analytical grade and were obtained from Aldrich and Acros. Purified water $(18 \mathrm{M} \Omega \cdot \mathrm{cm})$ from a Milli-Q water purification system (Millipore, Bedford, MA, USA) was used to prepare the standard salt and buffer solutions. All standard solutions were protected from light and kept at $4{ }^{\circ} \mathrm{C}$ in a refrigerator.

\subsection{Synthesis and Characterization of C-Dots}

For the capacitively coupled plasma (CCP) treatment, a crucible containing a mixture of an aliphatic acid $(100 \mathrm{mg})$ and a viscous solvent $(500 \mu \mathrm{L})$ was placed on a flat aluminum tray adapted for a cylindrical, stainless-steel, low pressure chamber (diameter of $10 \mathrm{~cm}$ and depth of $27.8 \mathrm{~cm}$ ), which was evacuated by a rotary vane pump $\left(3.0 \mathrm{~m}^{3} \cdot \mathrm{h}^{-1}\right)$ in a modular plasma system (Femto SRS, Diener electronic $\mathrm{GmbH}+\mathrm{Co}$. KG, Ebhausen, Germany). The system was initiated by an RF generator $(13.56 \mathrm{MHz}, 0 \sim 100 \mathrm{~W})$ to discharge the inlet gas $\left(\mathrm{O}_{2}\right.$ or $\left.\mathrm{N}_{2}\right)$ between an aluminum planar electrode and the flat tray under a working pressure of 0.285 torr. The gas flow was manually adjusted by a 
needle valve $(0 \sim 50 \mathrm{sccm})$, and the chamber pressure was measured by a Pirani sensor $\left(10^{-2} \sim 10 \mathrm{mbar}\right)$. The small-footprint, table-top system was semi-automatically processed through evacuation pumping, gas inlet, plasma ignition, and ventilation. For comparison, the crucible was placed in a domestic microwave oven $(0 \sim 1150$ Watt, $2450 \mathrm{MHz})$ or in a Teflon-lined vessel, sealed in a stainless-steel autoclave $(50 \mathrm{~mL})$ and calcined at a constant temperature $\left(200^{\circ} \mathrm{C}\right)$ for a specified period of time.

After treatment, the crucible was rinsed with $1.0 \mathrm{~mL}$ of $\mathrm{H}_{2} \mathrm{O}$ to collect the synthesized C-dot products. The $1.0 \mathrm{~mL} \mathrm{C}$-dot solutions were diluted at different ratios with water for characterization or with phosphate buffers ( $50 \mathrm{mM}, \mathrm{pH} 7.0)$ to build a calibration curve. The diluted aqueous solutions were characterized by a ultraviolet-visible (UV-Vis) spectrometer (Lambda 35, Perkin Elmer, Cambridge, MA, USA), spectrofluorometer (LS55, Perkin Elmer, Cambridge, MA, USA), Fourier transform infrared (FTIR) spectrometer (Prestige-21, Shimadzu, Japan) equipped with a single reflection horizontal ATR accessory (MIRacle, PIKE Technologies, Fitchburg, WI, USA), high-resolution transmission electron microscopy (JEM-2100, JEOL, Tokyo, Japan) operated at an accelerating voltage of $200 \mathrm{kV}$, and laboratory-built electrophoresis apparatus consisting of a $\pm 30 \mathrm{kV}$ high-voltage power supply (TriSep TM-2100, Unimicro Technologies, Pleasanton, CA, USA) and a UV-Vis detector (LCD 2083.2 CE, ECOM, Prague, Czech). Some product solutions were dried to evaporate the water at $70{ }^{\circ} \mathrm{C}$ in a vacuum oven for $24 \mathrm{~h}$ to prepare solid samples for high-resolution X-ray diffraction (D8 Discover, Bruker, MA, USA) and X-ray photoelectron spectroscopy (ULVAC-PHI PHI 5000 VersaProbe, Physical Electronics, Eden Prairie, MN, USA). Some product solutions $(1.0 \mathrm{~mL})$ were dialyzed against ultra-pure water through a molecular weight cutoff membrane (500-1000 Dalton, Float-A-Lyzer G2, $1 \mathrm{~mL}$ capacity, Spectrum Laboratories Inc., Savannah, GA, USA) to study the effect of the dialysis on the separation of the C-dot products.

\subsection{Fluorescence Measurement of Samples with the CCP-Treated C-Dots}

The CCP treatment of the mixture of citric acid $(100 \mathrm{mg})$ and the ionic liquid $(500 \mu \mathrm{L})$ [EMIM] $(\mathrm{CN})_{2}$ was performed with $10 \mathrm{sccm} \mathrm{O}_{2}$ inlet, 90 Watt RF power, and a $30 \mathrm{~min}$ duration. The as-prepared $1.0 \mathrm{~mL}$ C-dot solution possessed high fluorescence intensity and was capable of sensing samples. A small volume $(0.2 \mu \mathrm{L})$ of the $\mathrm{C}$-dot solution was added to each sample containing metal ions $(33.3 \mu \mathrm{M})$ or flavonoids $(8.33 \mu \mathrm{g} / \mathrm{mL})$ in $3.0 \mathrm{~mL}$ of phosphate buffer $(50 \mathrm{mM}, \mathrm{pH} 7.0)$ to measure the fluorescence intensities (I) at $430 \mathrm{~nm}$ (excitation at $330 \mathrm{~nm}$ ) and $480 \mathrm{~nm}$ (excitation at $390 \mathrm{~nm}$ ). These $I$ values were compared with those $\left(I_{0}\right)$ observed in the blank samples to evaluate the quenching effect $\left(I / I_{0}\right)$ on the samples and to further establish the calibration curves for quercetin, a flavonoid.

A flavonoid-rich traditional Chinese medicine (TCM), called "Guang-Chen-Pi" in Chinese, was purchased from a TCM store in Taichung, Taiwan, and the amount of quercetin in the medicine was determined. After cleaning with deionized water, $5.0 \mathrm{~g}$ of dried Guang-Chen-Pi was triturated and refluxed in $50 \mathrm{~mL}$ ethanol for two hours. After filtering through a glass microfiber disc (GF/A, Whatman, England), $25 \mathrm{~mL}$ of the filtrate was concentrated to dryness on a rotary evaporator. The remaining residue was dissolved with $7.2 \mathrm{~mL}$ ethanol and became the sample solution. Five $3.0 \mathrm{~mL}$ vials were each spiked with $6.0 \mu \mathrm{L}$ of the sample solution, and four of the five vials were further spiked with 1.0, 2.0, 3.0, and $4.0 \mu \mathrm{L}$ of the quercetin standard solution $\left(7.24 \times 10^{-3} \mathrm{M}\right)$. The quercetin in the ethanol extract of the Guang-Chen-Pi was calculated from the standard addition curve established by the $I$ values of the five vials.

\section{Results and Discussion}

\subsection{Choice of Short Aliphatic Acids and Solvents}

Four short aliphatic acids, including citric acid (CA), succinic acid, adipic acid, and malic acid (MA), were separately dispersed in high b.p. solvents, including glycerol, PEG 1000, PEI 600, and seven ionic liquids, which are listed in Section 2.1. Then, the mixtures were treated with the oxygen-gas 
(10 sccm), RF-discharge (90 Watt) plasma produced between the capacitive-coupling, parallel-plate electrodes. If lower b.p. solvents, such as ethylene glycol (b.p. $197^{\circ} \mathrm{C}$ ) and 1,4-butanediol (b.p. $235^{\circ} \mathrm{C}$ ), were substituted for the high b.p. solvents, a large amount of vaporized solvent was rapidly produced just after the plasma initiation, and the vacuum pumping and RF power were quickly stopped. If only the acids were treated by the capacitively coupled plasma (CCP) without the addition of solvents, the white powder products looked like the native, untreated acids and showed no fluorescence. After dispersion in the high b.p. solvents and a 30 min treatment with $\mathrm{O}_{2} / \mathrm{CCP}$, dark brown products were obtained, re-dispersed in water, and measured by UV-Vis and fluorescence spectroscopies. The observed spectra are shown in Table S1 in the Electronic supplementary information (ESI). Except for glycerol and PEG 1000, for which the CCP products did not show any fluorescence, most of the solvents had excitation-dependent emissions. Glycerol and PEG do not contain any nitrogen atoms in their chemical structures, but the other solvents do. The nitrogen involvement in $\mathrm{O}_{2} / \mathrm{CCP}$ carbonization of the acids is crucial for obtaining fluorescent C-dots. Although some fluorescent C-dots were obtained from non-nitrogen-containing materials by solvothermal [16], pyrolysis [17], hydrothermal [18], and microwave heating [19], nitrogen gas in air can enter the heating apparatuses and encounter the reactants to introduce nitrogen atoms into the $\mathrm{C}$-dot structures. Even heating glycerol or PEG solvents alone in a domestic microwave oven resulted in fluorescent C-dots [20,21]. In this study, the nitrogen in air could not enter the CCP vacuum chamber. The only nitrogen source was the high b.p. solvents. Currently, most fluorescent $\mathrm{C}$-dots are synthesized from nitrogen-containing carbon sources, solvents, or additives. In these cases, nitrogen-containing solvents act both as a dispersant and a passivant.

As shown in Table S1, the highest photoluminescence (PL) intensity $\left(I_{\max }\right)$ observed at the corresponding emission $\left(\lambda_{\mathrm{em}, \max }\right)$ and excitation $\left(\lambda_{\mathrm{ex}, \max }\right)$ wavelengths varied with the acid and nitrogen-containing solvent used. Some of the solvents, including PEI 600, [BMIM] $\mathrm{AlCl}_{4},[\mathrm{BMIM}] \mathrm{BF}_{4}$, and [MOIM]Cl, possessed similar $\lambda_{\mathrm{em} \text {,max }}$ and $\lambda_{\mathrm{ex}, \max }$ values for all the acids, but other solvents did not. Most of the CCP products possessed an obvious dependence of $\lambda_{\mathrm{em}}$ on $\lambda_{\mathrm{ex}}$, but a few of them did not. Interestingly, the $\mathrm{C}$-dots obtained from the $\mathrm{O}_{2} / \mathrm{CCP}$ treatment of CA and MA in [EMIM]N(CN $)_{2}$ possessed the first and second highest photoluminescence (PL) intensities among the CCP products in Table S1, but their dependence of $\lambda_{\mathrm{em}}$ on $\lambda_{\mathrm{ex}}$ was obscure. As shown in Figure 1a and Table S1, the emission redshifts were only $11 \mathrm{~nm}$ and $26 \mathrm{~nm}$ as an increase of $80 \mathrm{~nm}$ in $\lambda_{\text {ex }}$ was applied to the CA-based C-dots ( $350 \mathrm{~nm}$ to $430 \mathrm{~nm}$ ) and MA-based C-dots ( $300 \mathrm{~nm}$ to $380 \mathrm{~nm}$ ), respectively. In contrast, as shown in Figure 1(b), an obvious $58 \mathrm{~nm}$ redshift emission $\left(\lambda_{\mathrm{ex}}=350 \sim 430 \mathrm{~nm}\right)$ was observed for the $\mathrm{O}_{2} / \mathrm{CCP}$ of [EMIM]N $(\mathrm{CN})_{2}$ alone. Moreover, the $\lambda_{\mathrm{em} \text {,max }}$ position and the smaller PL intensity in Figure $1 \mathrm{~b}$ were different from those of the CA- and MA-based C-dots. There should be a synergistic effect of [EMIM]N $(\mathrm{CN})_{2}$ and the acids, CA and MA, on the formation of fluorescent C-dots in the $\mathrm{O}_{2} / \mathrm{CCP}$ carbonization. Further discussion about the independence of $\lambda_{\mathrm{ex}}$ for the CA-based C-dots is addressed in Section 3.2.

Instead of $\mathrm{O}_{2} / \mathrm{CCP}$, the $\mathrm{N}_{2} / \mathrm{CCP}$ treatment of $\mathrm{CA}$ in glycerol under the same CCP conditions converted non-fluorescent C-dots to fluorescent ones, as shown in Figure 1c, and they present a $\lambda_{\text {em,max }}$ of $400 \mathrm{~nm}$ with a $\lambda_{\mathrm{ex}, \max }$ of $330 \mathrm{~nm}$ and a $19 \mathrm{~nm}$ redshift emission with an excitation from $290 \mathrm{~nm}$ to $370 \mathrm{~nm}$. The definite difference in the fluorescence and UV-Vis spectra between Figure 1a,c implies the different routes of $\mathrm{C}$-dot formation. Although the $\mathrm{N}_{2} / \mathrm{CCP}$ treatment aided the use of non-nitrogen-containing glycerol, its PL intensity was much lower than that of the product from the $\mathrm{O}_{2} / \mathrm{CCP}$ treatment of CA in [EMIM]N $(\mathrm{CN})_{2}$ at the same dilution factor. Because a fluorophore with a high PL intensity is advantageous for analytical uses, CA dispersed in [EMIM]N $(\mathrm{CN})_{2}$ was selected to be the carbon source for the $\mathrm{O}_{2} / \mathrm{CCP}$ carbonization in the following discussion. 


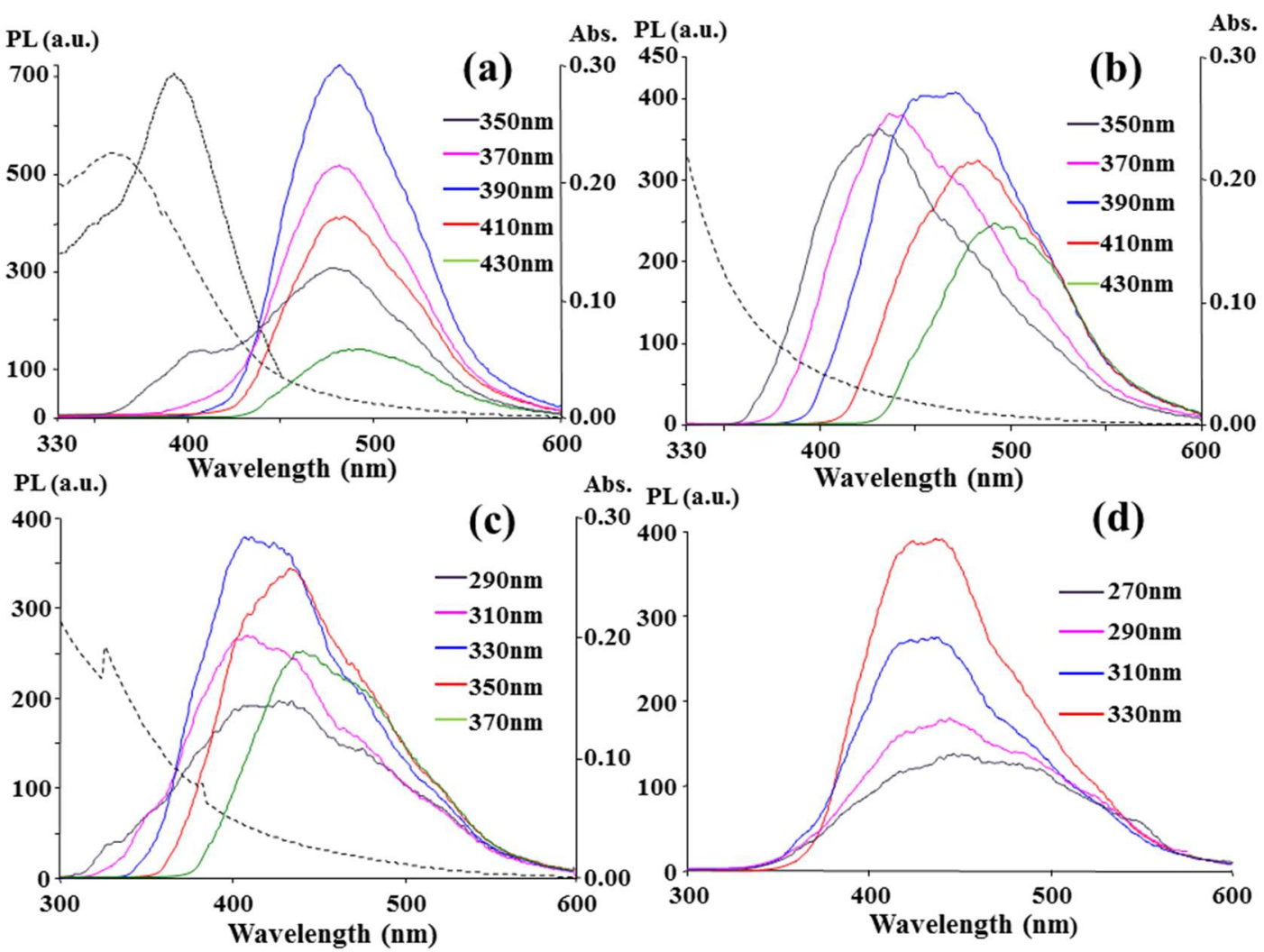

Figure 1. Fluorescence spectra of $(\mathbf{a}, \mathbf{d}) \mathrm{CA}+[\mathrm{EMIM}] \mathrm{N}(\mathrm{CN})_{2} ;(\mathbf{b})[\mathrm{EMIM}] \mathrm{N}(\mathrm{CN})_{2}$; and $(\mathbf{c}) \mathrm{CA}+$ glycerol treated by $\mathrm{O}_{2} / \mathrm{CCP}(\mathbf{a}, \mathbf{b}, \mathbf{d})$ and $\mathrm{N}_{2} / \mathrm{CCP}(\mathbf{c})$. The mixtures of $\mathrm{CA}(100 \mathrm{mg})$ and solvents $(500 \mu \mathrm{L})$ were treated by CCP (10 sccm of gas flow, RF power $90 \mathrm{~W}, 30 \mathrm{~min}$ ). After the addition of $1.0 \mathrm{~mL}$ of $\mathrm{H}_{2} \mathrm{O}$ to the treated products, different volumes of the product solutions $(0.2 \mu \mathrm{L}$ for $(\mathbf{a}, \mathbf{d})$ and $20 \mu \mathrm{L}$ for $(\mathbf{b}, \mathbf{c})$ were separately transferred to cuvettes filled with $3.0 \mathrm{~mL}$ of $\mathrm{H}_{2} \mathrm{O}$ for spectrometric measurements. $(-)$ and $(\cdots)$ curves denote UV-Vis absorption and PL (emission at $480 \mathrm{~nm}$ ) spectra, respectively.

\subsection{Characterization of CCP-Treated C-Dots}

The high-resolution TEM (HRTEM) image of the C-dots obtained in the conditions of Figure 1a is shown in Figure S1, and the average size of the 55 particles analyzed by the ImageJ freeware was $8.6 \mathrm{~nm}$ $(\sigma=1.1 \mathrm{~nm})$. Most of the C-dots did not have any clear lattice fringes in the HRTEM image, but a few indicated spaces between the graphene layers, as shown in Figure 2a and Figure S1. This was further supported by the X-ray diffraction (XRD) pattern in Figure $2 b$, which displayed a broad diffraction peak due to the amorphous nature of the sample and a distinct peak centered at $2 \theta=27.3^{\circ}$ for the (002) facet of graphite. The prepared C-dots would be classified as carbon quantum dots rather than carbon nanodots according to the classification in a recent paper [22]. Capillary zone electrophoresis was used to analyze the changes in the surface charge of the C-dots via the electrophoretic mobility $\left(\mu_{\mathrm{ep}}\right)$ at the $\mathrm{pH}$ of the running buffers. As shown in Figure $2 \mathrm{c}$, the $\mu_{\mathrm{ep}}$ values, which were determined by subtracting the electroosmotic mobilities $\left(\mu_{\text {eof }}\right)$ from the apparent mobilities $\left(\mu_{\text {app }}\right)$ and inferred net charge on the C-dot surface, were positive below $\mathrm{pH} 5.0$ and negative above $\mathrm{pH}$ 8.9. The dissociation of carboxylic acid and protonated amine or 1.3-diketones would occur on the C-dot surface as their pKa values are near to 5.0 and 8.9, respectively. The full scan of the XPS spectrum presents the main peaks of $\mathrm{C} 1 \mathrm{~s}, \mathrm{~N} 1 \mathrm{~s}$, and $\mathrm{O} 1 \mathrm{~s}$ in Figure $2 \mathrm{~d}$. The carbon content $(49.5 \%)$ in the $\mathrm{O}_{2} / \mathrm{CCP}$ product was reasonable and in the range between the reactants $\mathrm{CA}(\mathrm{C}: 37.5 \%)$ and $[\mathrm{EMIM}] \mathrm{N}(\mathrm{CN})_{2}(\mathrm{C}: 58.9 \%)$. However, a large decrease in the oxygen percentage from $58.3 \%$ in $\mathrm{CA}$ to $13.2 \%$ in the product was distinct from the slight increase in the nitrogen percentage from $34.4 \%$ in [EMIM] $(\mathrm{CN})_{2}$ to $37.4 \%$ in the product. This indicates that the oxygen atoms in CA were more easily subtracted by the oxygen plasma than 
the nitrogen atoms bound in the imidazole ring in [EMIM] $(\mathrm{CN})_{2}$. The deconvolution of the main peaks is shown in Figure S2. In detail, four peaks related to the $\mathrm{C}-\mathrm{C}(284.3 \mathrm{eV}), \mathrm{C}-\mathrm{N}(284.9 \mathrm{eV}), \mathrm{C}-\mathrm{O}$ $(285.9 \mathrm{eV})$, and $\mathrm{C}=\mathrm{O} / \mathrm{C}=\mathrm{N}(287.6 \mathrm{eV})$ functional groups were deconvoluted from the $\mathrm{C} 1 \mathrm{~s}$ spectrum. The $\mathrm{N} 1 \mathrm{~s}$ spectrum contained three nitrogen bonding groups, including $\mathrm{C}-\mathrm{N}-\mathrm{C}(399.5 \mathrm{eV}), \mathrm{N}-(\mathrm{C})_{3}$ $(400.2 \mathrm{eV})$, and $\mathrm{N}-\mathrm{H}(401.9 \mathrm{eV})$. The $\mathrm{O} 1 \mathrm{~s}$ spectrum contained two characteristic peaks corresponding to the $\mathrm{C}=\mathrm{O}(530.7 \mathrm{ev})$ and $\mathrm{C}-\mathrm{OH} / \mathrm{C}-\mathrm{O}-\mathrm{C}(532.3 \mathrm{eV})$ groups. Although the peaks of $\mathrm{C}=\mathrm{N}$ and $\mathrm{N}-(\mathrm{C})_{3}$ may support the existence of the imidazole group, the peaks for $\mathrm{C}-\mathrm{N}, \mathrm{C}-\mathrm{N}-\mathrm{C}$, and $\mathrm{N}-\mathrm{H}$ imply that parts of the imidazole rings were pyrolyzed. Further evidence of the decomposition of imidazole rings was given by the FTIR spectra in Figure 2e, which show that the characteristic absorption bands of the aromatic $\mathrm{CN}$ heterocycles observed at 1465 to $1600 \mathrm{~cm}^{-1}$ in [EMIM]N $(\mathrm{CN})_{2}$ disappeared after the $\mathrm{O}_{2} / \mathrm{CCP}$ treatment. Even the dicyanamide anion decomposed, and its $\mathrm{C} \equiv \mathrm{N}$ group absorption at $2145 \mathrm{~cm}^{-1}$ also vanished after the plasma action. The other typical peaks of the plasma product were recognized as specific chemical bonding in Figure 2e.

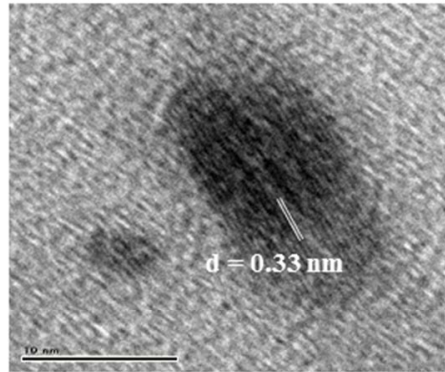

(a)

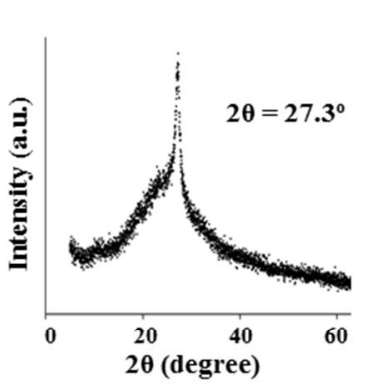

(b)

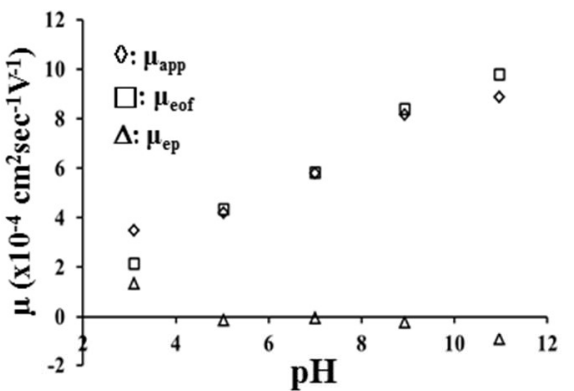

(c)

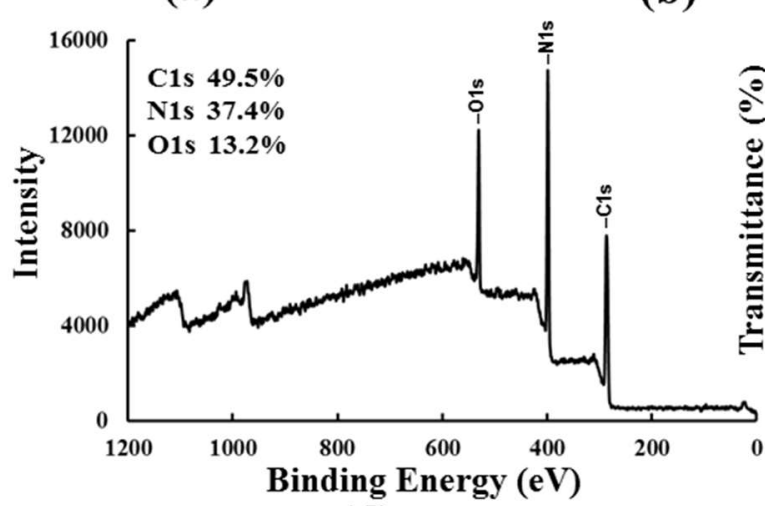

(d)

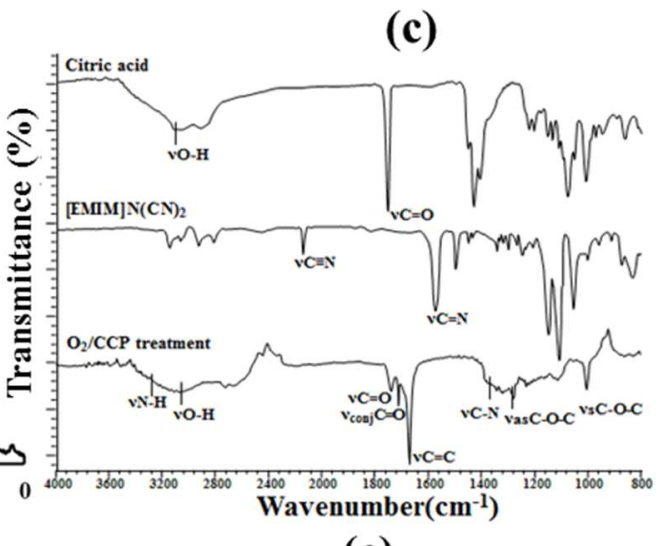

(e)

Figure 2. Characterization of the C-dots prepared in the conditions of Figure 1a. (a) HRTEM image; (b) XRD spectrum; (c) the plot of mobility with the $\mathrm{pH}$ of the running buffers; (d) XPS spectrum, and (e) FTIR spectrum.

The PL, PLE (PL excitation), and UV-Vis absorption spectra of the as-prepared C-dots are shown in Figure 1a, and an excitation-independent PL and an absorption peak at $360 \mathrm{~nm}$, which was different from $\lambda_{\text {ex, } \max }=390 \mathrm{~nm}$, were observed. The emission at approximately $480 \mathrm{~nm}$ is independent of the excited light beam from $350 \mathrm{~nm}$ to $430 \mathrm{~nm}$. At $\lambda_{\text {ex,max }}=390 \mathrm{~nm}$, the quantum yield of the C-dots was $12.4 \%$ based on a calibration against the reference quinine sulfate in $0.5 \mathrm{M} \mathrm{H}_{2} \mathrm{SO}_{4}$, as shown in Figure S3. The same phenomenon occurred in Figure 1d, and the excited light beam from 270 to $330 \mathrm{~nm}$ produced another independent emission at approximately $430 \mathrm{~nm}$ for the C-dots. At $\lambda_{\mathrm{ex}, \max }=330 \mathrm{~nm}$, the quantum yield was calculated to be $7.2 \%$ with reference to 2-aminopyridine in $0.5 \mathrm{M} \mathrm{H}_{2} \mathrm{SO}_{4}$, as shown in Figure S3. The two $\lambda_{\text {ex }}$-independent emissions at $430 \mathrm{~nm}$ and $480 \mathrm{~nm}$ indicate two emissive states for each uniform energy distribution on the C-dots. Neither of the two emissions could 
be categorized as an intrinsic emission $\left(\pi^{*} \rightarrow \pi\right)$ from the carbon core because the quantum confinement effect determines that $8.6 \mathrm{~nm}$ in diameter C-dots would have a longer-wavelength emission than near infrared but not visible emissions [23]. The molecule states, which are determined solely by the fluorescent molecules connected on the surface or interior of the C-dots, may be emissive states because $\lambda_{\mathrm{ex}}$ independence is a characteristic of a molecule state [24-27]. However, the possibility of forming molecule states on the C-dots was excluded because no reasonable route to form a fluorophore molecule via the reaction of CA and [EMIM]N $(\mathrm{CN})_{2}$ could be inferred, whereas fluorophores were reasonably formed by the reaction of $\mathrm{CA}$ and a primary amine, such as ethanolamine and ethylene diamine [24,27]. Therefore, the two emissions should come from the surface states, which consisted of hybridization of the carbon backbone and the connected chemical groups because the $\pi^{*}$ and molecule states were excluded as the emissive states [28].

A dialysis membrane (cellulose ester, 500-1000 Da molecular weight cut-off) was used as an ultrafilter for the as-prepared C-dots to separate the two surface states. As shown in Figure 3a, the $430 \mathrm{~nm}$ emission of the dialyzed C-dots that collected outside the membrane grew stronger after the first $2 \mathrm{~h}$ dialysis, but the $480 \mathrm{~nm}$ emission was weaker than that inside the membrane. Moreover, the UV absorption peak at approximately $360 \mathrm{~nm}$ for the dialyzed C-dots vanished, and this could be related to the weakness of the $480 \mathrm{~nm}$ emission. The fluorescence spectra of the C-dots dialyzed at various times are assembled in Figure S4, and the changes in the ratio of the PL intensity at $430 \mathrm{~nm}$ to that at $480 \mathrm{~nm}$ with the dialysis time are plotted in Figure 3b. The plot shows that the C-dot particles with higher ratio values penetrate through membrane faster than those with lower ratios, and each as-prepared C-dot particle did not have a uniform surface composition with an identical PL intensity ratio. The faster penetration was apparently not due to the smaller particle size because the average diameter $(3.1 \mathrm{~nm}, \sigma=1.0 \mathrm{~nm})$ of the C-dots dialyzed for the first two hours was close to that $(3.6 \mathrm{~nm}, \sigma=1.1 \mathrm{~nm})$ for those dialyzed for $8 \mathrm{~h}$, as shown in Figure S5. The main reason for different penetration rate is that some of the functional groups or surface states leading to the $430 \mathrm{~nm}$ emission favored penetration, but other surface states that lead to the $480 \mathrm{~nm}$ emission did not favor penetration. These two groups simultaneously collected on a C-dot particle, but the buildup of the groups on the particles was in different mole ratios. Figure $3 c$ shows a possible energy level diagram for a C-dot particle. For the two emissions, the excitation radiation beams actuated the valence $\pi$ electrons in the core of the C-dot particle to the $\pi^{*}$ conduction band. Then, the excited electrons transitioned to the emissive surface states via radiationless relaxation between the lower $\pi^{*}$ levels and/or their hybrid states, which were hybridized with core carbon and heteroatoms, such as nitrogen and oxygen atoms, during the nucleation step in the carbonation.

The upconversion emission at $\lambda_{\mathrm{em}, \max }=480 \mathrm{~nm}$ was observed for the C-dots with 710-790 nm excitation $\left(\lambda_{\text {ex, } \max }=790 \mathrm{~nm}\right)$, as shown in Figure S6. The emission intensity increased with the excitation wavelength. A longer-wavelength light than $800 \mathrm{~nm}$ was not available due to the limitations of the fluorospectrophotometer used in this study, but a longer wavelength source, such as a near-IR laser, might induce a higher PL intensity. A $790 \mathrm{~nm}$ light stimulated the $480 \mathrm{~nm}$ up-conversion emission, and a $390 \mathrm{~nm}$ light also stimulated the $480 \mathrm{~nm}$ emission, as shown in Figure 1a. This was expected because $790 \mathrm{~nm}$ is nearly double $390 \mathrm{~nm}$ and is suitable for the sequential absorption of two long wavelength photons. However, a $430 \mathrm{~nm}$ up-conversion emission was not observed in the excitation range from 430 to $790 \mathrm{~nm}$. The $\pi^{*}$ transit states $(2 \lambda=660 \mathrm{~nm})$ that correlated with the $430 \mathrm{~nm}$ emission at $\lambda_{\text {ex,max }}=330 \mathrm{~nm}$, as shown in Figure $1 \mathrm{~d}$, would be less stable for the sequential absorption than those $(2 \lambda=780 \mathrm{~nm})$ that correlated with the $480 \mathrm{~nm}$ and underwent radiationless relaxation. 

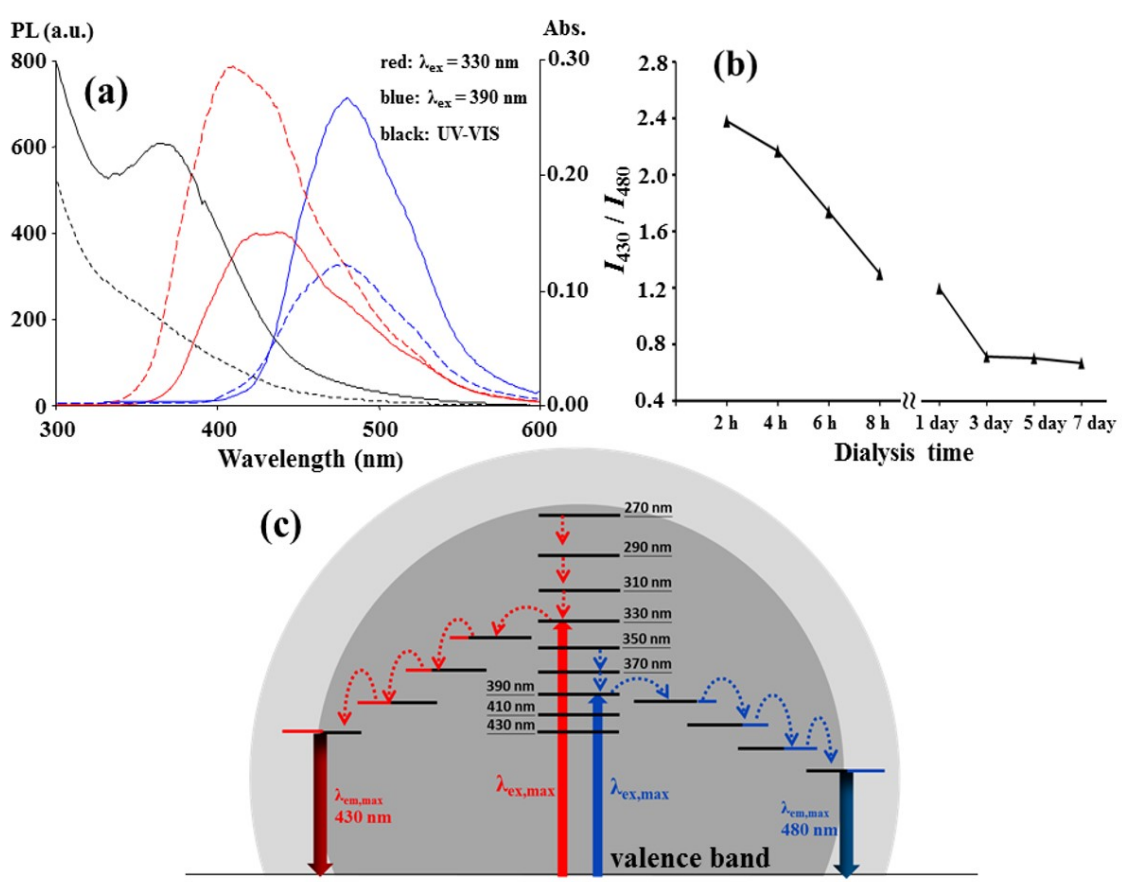

Figure 3. (a) Fluorescence and UV-Vis absorption spectra of the C-dots prepared in the conditions of Figure 1a before (solid lines) and after (dashed lines) dialysis in $\mathrm{H}_{2} \mathrm{O}$ by a 500-1000 Da cut-off membrane for two hours; (b) The plot of the PL intensity ratios of $430 \mathrm{~nm}$ PL intensity to $480 \mathrm{~nm}$ PL intensity with the dialysis duration; (c) The proposed PL mechanism.

\subsection{Comparison between CCP, Microwave, and Hydrothermal Carbonation}

For a comparison, $\mathrm{CA}$ and [EMIM]N $(\mathrm{CN})_{2}$ were mixed in a crucible and heated in a domestic microwave oven at 90 Watt. The heating was stopped after 4.5 min because a severe burning flame appeared on the crucible during the microwave irradiation. As shown in Figure 4a, the microwave-treated product emission at $430 \mathrm{~nm}$ is stronger than its emission at $480 \mathrm{~nm}$. Therefore, the number of surface states corresponding to the $430 \mathrm{~nm}$ emission should be larger than the number corresponding to the $480 \mathrm{~nm}$ emission. Furthermore, the chemical composition corresponding to the two surface states caused by microwave radiation with a sufficient oxygen supply should be different from that caused by the CCP ion bombardment under a limited oxygen supply. The stronger $430 \mathrm{~nm}$ emission obtained with a sufficient oxygen supply implied that the formation of the $430 \mathrm{~nm}$ emissive surface states involved oxygen atoms. Figure 4 a shows the $\lambda_{\text {ex,max }}$ was $370 \mathrm{~nm}$ or $390 \mathrm{~nm}$ for the maximum emission at $\lambda_{\mathrm{em}, \max }=430 \mathrm{~nm}$, and the $\lambda_{\mathrm{ex}, \max }$ was $430 \mathrm{~nm}$ for that at $\lambda_{\mathrm{em}, \max }=480 \mathrm{~nm}$. The two $\lambda_{\text {ex,max }}$ values are larger (approximately $40 \mathrm{~nm}$ ) than those in Figure $1 \mathrm{~d}\left(\lambda_{\mathrm{ex}, \max }=330 \mathrm{~nm}\right)$ and Figure $1 \mathrm{a}\left(\lambda_{\mathrm{ex}, \max }=390 \mathrm{~nm}\right)$, respectively. In addition to the changes in the surface composition, the severe carbonation in a microwave oven might extend the domain of the double bond and shrink the energy gap between $\pi$ and $\pi^{*}$ to cause the $40 \mathrm{~nm}$ redshift compared with that for the CCP treatment. Without the addition of $\mathrm{CA}$, heating [EMIM]N $(\mathrm{CN})_{2}$ alone in a microwave could not provide the considerable $480 \mathrm{~nm}$ emission and only resulted in a strong $430 \mathrm{~nm}$ emission $\left(\lambda_{\mathrm{em}, \max }=400 \mathrm{~nm}\right)$ at a shorter $\lambda_{\text {ex }}(290 \sim 350 \mathrm{~nm})$, as shown in Figure $4 \mathrm{~b}$. In comparison with Figure $4 \mathrm{a}$, the participation of CA in the carbonation could mainly contribute the $480 \mathrm{~nm}$ emissive states and the extension of the conjugated double bonds to the $\mathrm{C}$-dot structure.

The mixture of CA and [EMIM] $(\mathrm{CN})_{2}$ was also placed in a Teflon-lined autoclave and heated in a hot-air oven at $200{ }^{\circ} \mathrm{C}$ for $30 \mathrm{~min}$. The PL and UV-Vis absorption spectra of the hydrothermal products are plotted in Figure $4 \mathrm{c}$ and are similar to those in Figure 1a, which were obtained from $\mathrm{O}_{2} / \mathrm{CCP}$ at $10 \mathrm{sccm}$, except the PL intensity was smaller than that in Figure 1a. Furthermore, the spectrum of the [EMIM] $\mathrm{N}(\mathrm{CN})_{2}$ alone sample treated by a hydrothermal method was similar to that from the CCP 
method, i.e., comparison of Figure $4 \mathrm{~d}$ with Figure $1 \mathrm{~b}$. It is believed that fine tuning the temperature and duration of the hydrothermal reaction in an autoclave could enhance the similarity of the reaction to the CCP carbonation in a vacuum chamber with a low $\mathrm{O}_{2}$ supply, i.e., $10 \mathrm{sccm}$ in our system. Figure $4 \mathrm{~d}$ shows the results from $5.0 \mathrm{~h}$ of heating [EMIM]N $(\mathrm{CN})_{2}$ alone in an autoclave. Only $30 \mathrm{~min}$ of heating by the hydrothermal method could not obtain a PL spectrum, but Figure 1 b spectrum by the $\mathrm{O}_{2} / \mathrm{CCP}$ method was obtained.

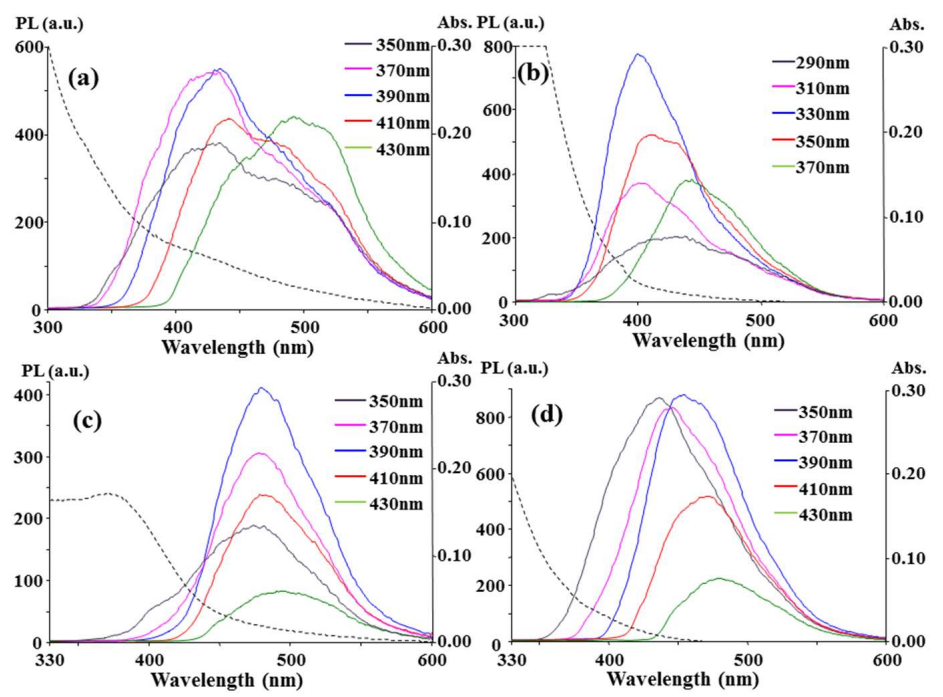

Figure 4. Fluorescence and UV-Vis absorption spectra for the CA $+[\mathrm{EMIM}] \mathrm{N}(\mathrm{CN})_{2}(\mathrm{a}, \mathrm{c})$ and [EMIM]N $(\mathrm{CN})_{2}$ alone $(\mathbf{b}, \mathbf{d})$ samples heated in a $90 \mathrm{~W}$ microwave oven for $4.5 \mathrm{~min}(\mathbf{a}, \mathbf{b})$ and in an autoclave at $200{ }^{\circ} \mathrm{C}$ for $30 \mathrm{~min}(\mathbf{c})$ and $5.0 \mathrm{~h}$ (d). After the addition of $1.0 \mathrm{~mL} \mathrm{of} \mathrm{H}_{2} \mathrm{O}$ to the heated products, the product solutions of $0.2 \mu \mathrm{L}$ for (a); $0.3 \mu \mathrm{L}$ for (b); $2.0 \mu \mathrm{L}$ for (c); and $15 \mu \mathrm{L}$ for (d) were diluted with $3.0 \mathrm{~mL}$ of $\mathrm{H}_{2} \mathrm{O}$ to measure the spectra.

\subsection{Fluorescent Sensing by the $\mathrm{O}_{2} / \mathrm{CCP}$-Treated C-Dots}

The fluorescent C-dots prepared by $\mathrm{O}_{2} / \mathrm{CCP}$ of a mixture of CA and [EMIM]N(CN $)_{2}$ in the conditions shown in the legend of Figure 1a were used to separately probe fifteen metal ions and nine flavonoids. At first, the $\lambda_{\text {ex }}$-independent emissions at $430 \mathrm{~nm}\left(\lambda_{\mathrm{ex}, \max }=330 \mathrm{~nm}\right)$ and $480 \mathrm{~nm}$ $\left(\lambda_{\text {ex } \max }=390 \mathrm{~nm}\right)$ of the C-dots were used to evaluate their responses to the analytes. The $480 \mathrm{~nm}$ emission was quenched by $\mathrm{Cu}^{2+}, \mathrm{Ag}^{+}$, and $\mathrm{Hg}^{2+}$, while the $430 \mathrm{~nm}$ emission was further quenched by $\mathrm{Fe}^{3+}$ in addition to those ions, as shown in Figure 5a, where $I$ and $I_{0}$ are the emission intensities in the absence and presence of the sample, respectively. The ions, $\mathrm{Fe}^{3+}, \mathrm{Cu}^{2+}$, and $\mathrm{Ag}^{+}$, quenched 10 15\% of each emission, and nearly $30 \%$ of the $430 \mathrm{~nm}$ emission and $65 \%$ of the $480 \mathrm{~nm}$ emission could be heavily quenched by $\mathrm{Hg}^{2+}$. The quenching was sensitive to $\mathrm{Hg}^{2+}$, especially the $480 \mathrm{~nm}$ emission, but the coexistence of the $\mathrm{Fe}^{3+}, \mathrm{Cu}^{2+}$, and $\mathrm{Ag}^{+}$ions in a real sample would interfere with the detection of $\mathrm{Hg}^{2+}$. However, the synthetic $\mathrm{C}$-dots are good starting fluorescent materials for further ligand attachment on them to improve a sensor's specificity for $\mathrm{Hg}^{2+}$ in the presence of interfering ions.

For the flavonoid samples, quercetin, hesperetin, and naringenin could quench nearly half of the $430 \mathrm{~nm}$ emission, but daidzein and 5-methoxyflavone passivated some unknown surface traps and enhanced the $430 \mathrm{~nm}$ PL intensity, as shown in Figure 5b. In contrast to the $430 \mathrm{~nm}$ emission, the $480 \mathrm{~nm}$ emission was only selectively quenched by quercetin, and the other flavonoids did not affect the $480 \mathrm{~nm}$ emission. Therefore, the C-dots would directly sense quercetin in a flavonoid-rich sample, such as Citrus reticulata cv. Chachiensis, which is a sun-dried peel used as a traditional Chinese medicine, called "Guang-Chen-Pi" in Chinese. For quantification, the $480 \mathrm{~nm}$ PL intensities were measured (Figure 5c) after equilibrium with quercetin standards in a phosphate buffer, pH 7.0, $50 \mathrm{mM}$, and they were plotted against the quercetin concentrations ranging from $2.4 \mu \mathrm{M}$ to $119 \mu \mathrm{M}$ in Figure $5 \mathrm{~d}$. 
As shown in Figure $5 d$, the Stern-Volmer plot, $I_{0} / I$ v.s. [quercetin], is not linear. The deviation from linearity is frequently attributed to a combination of dynamic and static quenching and can be corrected using a modified Stern-Volmer plot, i.e., the Perrin model:

$$
\ln \left(I_{0} / I\right)=N_{\mathrm{A}} V[\text { Quencher] }
$$

where $\alpha=N_{\mathrm{A}} V$, where $N_{\mathrm{A}}$ is Avogadro's number and $V$ is the volume of the active sphere of quenching. Based on the good linearity $\left(R^{2}=0.9992\right)$ and high slope $\left(1.96 \times 10^{4} \mathrm{M}^{-1}\right)$ of the Perrin relationship, the radius of the effective quenching sphere was calculated to be $19.8 \mathrm{~nm}$, which is 2.3 times the C-dot radius $(8.6 \mathrm{~nm})$ and allowed an efficient, photoinduced electron-transfer process of the encounter pair between the C-dot (as an electron donor) and quercetin (as an electron acceptor) without coupling reagents. The relative standard deviation for seven replicate measurements of $12.1 \mu \mathrm{M}$ quercetin solutions was $3.3 \%$. Based on the $3 \sigma$ of the blank response $(\sigma=3.1 \%, n=10)$, the detection limit was calculated to be $0.5 \mu \mathrm{M}$. As shown in the inset of Figure $5 \mathrm{~d}$, the quercetin in the ethanol extract of Guang-Chen-Pi was determined by a standard addition method to be $4.20 \pm 0.15 \mathrm{mg} / \mathrm{g}$, which was nearly nine times higher than $0.47 \mathrm{mg} / \mathrm{g}$ found in the air-dried peel of Citrus reticulate Blanco [29]. Some factors, such as the citrus species used, growth environment, and method of drying the peel, accounted for the difference. The matrix effect was evaluated by the ratio defined as $\left(S_{1}-S_{2}\right) \times 100 \% / S_{2}$, where $S_{1}$ and $S_{2}$ are the slopes of the calibration curves obtained by standard addition $\left(S_{1}=2.12 \times 10^{4} \mathrm{M}^{-1}\right.$, $\left.R^{2}=0.9990\right)$ and external standard $\left(S_{2}=1.96 \times 10^{4} \mathrm{M}^{-1}\right)$ methods, respectively [30]. The calculated ratio, $8.16 \%$, was lower than $10 \%$, which suggested that the matrix effect could be ignored by the standard addition method. The selectivity of the $480 \mathrm{~nm}$ emission from the C-dots for quercetin helped reduce the matrix effect.
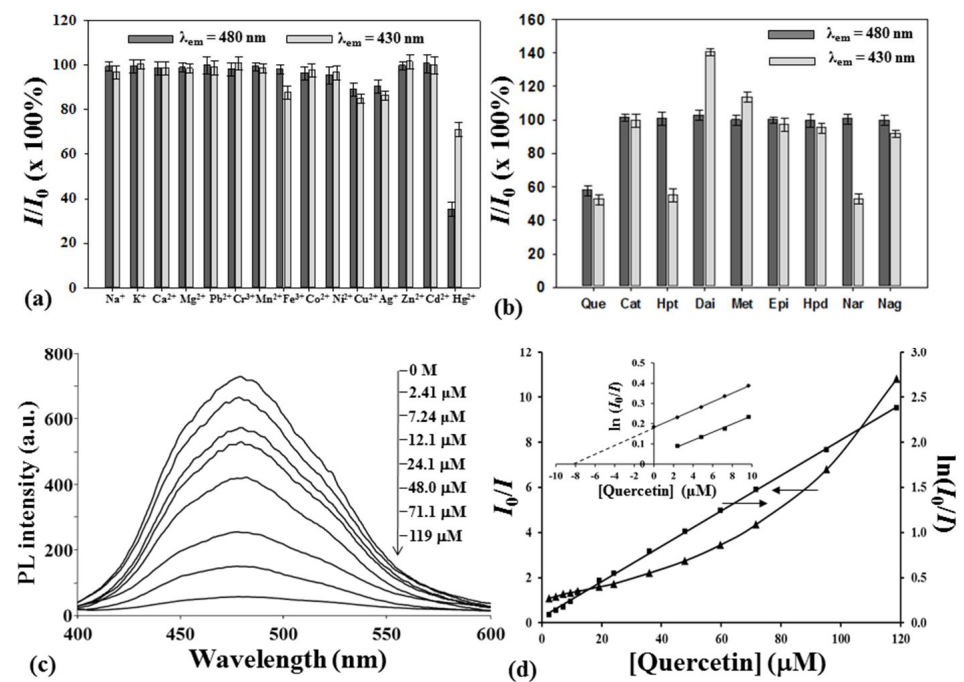

Figure 5. Effect of different metal ions $(33.3 \mu \mathrm{M})(\mathbf{a})$ and flavonoids $(8.33 \mu \mathrm{g} / \mathrm{mL})(\mathbf{b})$ on the relative PL intensity $\left(I / I_{0}\right)$ of the C-dots prepared in the conditions of Figure 1a; (c): Emission spectra of the prepared C-dots before and after the addition of various concentrations of quercetin; (d): The respective emission intensities are plotted versus the quercetin concentrations according to the Stern-Volmer $(\boldsymbol{\Delta})$ and Perrin ( $\mathbf{\square})$ models. The curve of the standard addition calibration ( $)$ for the determination of quercetin in the ethanol extract of Guang-Chen-Pi is inserted in (d). I and $\mathrm{I}_{0}$ are the PL intensities observed in the presence $(I)$ and absence $\left(I_{0}\right)$, respectively, of the samples in a $50 \mathrm{mM}$ phosphate buffer at $\mathrm{pH} 7.0$.

\section{Conclusions}

The use of $\mathrm{O}_{2} / \mathrm{CCP}$ in the carbonation of mixtures of aliphatic acids and nitrogen-containing viscous liquids, such as ionic liquids and PEI, was successful in forming fluorescent molecules. 
The dispersion of citric acid in [EMIM]N $(\mathrm{CN})_{2}$ possessed the highest fluorescence intensity among the mixtures, and the characteristics of the carbon quantum dots with $\mathrm{C}-\mathrm{N}, \mathrm{C}-\mathrm{O}, \mathrm{O}-\mathrm{H}$, and $\mathrm{N}-\mathrm{H}$ functionalities were two excitation-independent emissions emerging from two surface states and upconversion of the fluorescence. In a comparison of the fluorescence spectra, the CCP-treated C-dots were similar to the hydrothermally synthesized ones because they were operated in an oxygen-limited environment, but they were different from the MW-irradiated ones in an open environment. With specificity for quercetin among nine flavonoids, the CCP-treated C-dots were applied to determine the quercetin content in Guang-Chen-Pi, $4.20 \pm 0.15 \mathrm{mg} / \mathrm{g}$. Among fifteen metal ions, mercury ions most effectively quenched the fluorescence of the CCP-treated C-dots. Instead of $\mathrm{O}_{2} / \mathrm{CCP}$, the $\mathrm{N}_{2} / \mathrm{CCP}$ treatment of citric acid in glycerol under the same CCP conditions converted non-fluorescent $\mathrm{C}$-dots to fluorescent ones. This CCP-gas system can, not only provide carbonization of carbonaceous materials but doping of heteroatoms or afterwards.

Supplementary Materials: The following are available online at http:/ www.mdpi.com/2079-4991/8/6/372/s1, Figure S1: TEM images of the as-prepared C-dots; Figure S2: The deconvolution of the C 1s, N 1s, and O 1s XPS peaks from the $\mathrm{O}_{2} / \mathrm{CCP}$ of the mixture of CA and [EMIM]N(CN)$)_{2}$; Figure S3: Plot of the normalized PL intensity against the UV-Vis absorbance for the determination of the quantum yield; Figure S4: The fluorescence spectra of the C-dots collected after different dialysis times; Figure S5: TEM images of the C-dots dialyzed for two hours and their size distribution; Figure S6: Up-conversion emissions of the prepared C-dots under different wavelength excitations; Table S1: The UV-Vis and fluorescence spectra of the products obtained by CCP treatments.

Author Contributions: J.-L.C. supervised the experiments and assured the high quality of the scientific content. C.-B.K. and T.-L.L. conducted experiments and wrote the paper. All authors read and approved the final manuscript.

Acknowledgments: Support for this work by the Ministry of Science and Technology of Taiwan under Grant no. MOST-106-2113-M-039-006 and the China Medical University under Grant no. CMU106-S-17 is gratefully acknowledged.

Conflicts of Interest: The authors declare no conflict of interest.

\section{References}

1. Qi, B.-P.; Bao, L.; Zhang, Z.-L.; Pang, D.-W. Electrochemical methods to study photoluminescent carbon nanodots: Preparation, photoluminescence mechanism and sensing. ACS Appl. Mater. Interfaces 2016, 8, 28372-28382. [CrossRef] [PubMed]

2. Du, Y.; Guo, S. Chemically doped fluorescent carbon and graphene quantum dots for bioimaging, sensor, catalytic and photoelectronic applications. Nanoscale 2016, 8, 2532-2543. [CrossRef] [PubMed]

3. Gao, X.; Du, C.; Zhuang, Z.; Chen, W. Carbon quantum dot-based nanoprobes for metal ion detection. J. Mater. Chem. C 2016, 4, 6927-6945. [CrossRef]

4. Namdari, P.; Negahdari, B.; Eatemadi, A. Synthesis, properties and biomedical applications of carbon-based quantum dots: An updated review. Biomed. Pharmacother. 2017, 87, 209-222. [CrossRef] [PubMed]

5. Miao, P.; Han, K.; Tang, Y.; Wang, B.; Lin, T.; Cheng, W. Recent advances in carbon nanodots: Synthesis, properties and biomedical applications. Nanoscale 2015, 7, 1586-1595. [CrossRef] [PubMed]

6. Zheng, X.T.; Ananthanarayanan, A.; Luo, K.Q.; Chen, P. Glowing graphene quantum dots and carbon dots: Properties, syntheses, and biological applications. Small 2015, 11, 1620-1636. [CrossRef] [PubMed]

7. Ostrikov, K.; Neyts, E.C.; Meyyappan, M. Plasma nanoscience: From nano-solids in plasmas to nano-plasmas in solids. Adv. Phys. 2013, 62, 113-224. [CrossRef]

8. Jiang, H.; Chen, F.; Lagally, M.G.; Denes, F.S. New strategy for synthesis and functionalization of carbon nanoparticles. Langmuir 2010, 26, 1991-1995. [CrossRef] [PubMed]

9. Wang, Z.; Lu, Y.; Yuan, H.; Ren, Z.; Xu, C.; Chen, J. Microplasma-assisted rapid synthesis of luminescent nitrogen-doped carbon dots and their application in $\mathrm{pH}$ sensing and uranium detection. Nanoscale 2015, 7, 20743-20748. [CrossRef] [PubMed]

10. Wang, B.B.; Chen, C.C.; Zheng, K.; Cheng, Q.J.; Wang, L.; Wang, R.Z. Comparative study of the carbon nanofilm and nanodots grown by plasma-enhanced hot filament chemical vapor deposition. Mater. Sci. Semicond. Process. 2014, 21, 146-153. [CrossRef] 
11. Kim, J.; Suh, J.S. Size-controllable and low-cost fabrication of graphene quantum dots using thermal plasma jet. ACS Nano 2014, 8, 4190-4196. [CrossRef] [PubMed]

12. Lee, M.W.; Kim, J.; Suh, J.S. Characteristics of graphene quantum dots determined by edge structures: Three kinds of dots fabricated using thermal plasma jet. RSC Adv. 2015, 5, 67669-67675. [CrossRef]

13. Wang, J.; Wang, C.-F.; Chen, S. Amphiphilic egg-derived carbon dots: Rapid plasma fabrication, pyrolysis process, and multicolor printing patterns. Angew. Chem. Int. Ed. 2015, 51, 9297-9301. [CrossRef] [PubMed]

14. Li, C.-X.; Yu, C.; Wang, C.-F.; Chen, S. Facile plasma-induced fabrication of fluorescent carbon dots toward high-performance white LEDs. J. Mater. Sci. 2013, 48, 6307-6311. [CrossRef]

15. Zhu, L.; Yin, Y.; Wang, C.-F.; Chen, S. Plant leaf-derived fluorescent carbon dots for sensing, patterning and coding. J. Mater. Chem. C 2013, 1, 4925-4932. [CrossRef]

16. Jia, X.; Wang, E. One-pot green synthesis of optically $\mathrm{pH}$-sensitive carbon dots with upconversion luminescence. Nanoscale 2012, 4, 5572-5575. [CrossRef] [PubMed]

17. Lai, C.-W.; Hsiao, Y.-H.; Peng, Y.-K.; Chou, P.-T. Facile synthesis of highly emissive carbon dots from pyrolysis of glycerol; gram scale production of carbon dots $/ \mathrm{mSiO}_{2}$ for cell imaging and drug release. J. Mater. Chem. 2012, 22, 14403-14409. [CrossRef]

18. Yang, Z.-C.; Wang, M.; Yong, A.M.; Wong, S.Y.; Zhang, X.-H.; Tan, H.; Chang, A.Y.; Li, X.; Wang, J. Intrinsically fluorescent carbon dots with tunable emission derived from hydrothermal treatment of glucose in the presence of monopotassium phosphate. Chem. Commun. 2011, 47, 11615-11617. [CrossRef] [PubMed]

19. Zhu, H.; Wang, X.; Li, Y.; Wang, Z.; Yang, F.; Yang, X. Microwave synthesis of fluorescent carbon nanoparticles with electrochemiluminescence properties. Chem. Commun. 2009, 5118-5120. [CrossRef] [PubMed]

20. Wang, X.; Qu, K.; Xu, B.; Ren, J.; Qu, X. Microwave assisted one-step green synthesis of cell-permeable multicolor photoluminescent carbon dots without surface passivation reagents. J. Mater. Chem. 2011, 21, 2445-2450. [CrossRef]

21. Jaiswal, A.; Ghosh, S.S.; Chattopadhyay, A. One step synthesis of C-dots by microwave mediated caramelization of poly(ethylene glycol). Chem. Commun. 2012, 48, 407-409. [CrossRef] [PubMed]

22. Cayuela, A.; Soriano, M.L.; Carrillo-Carrión, C.; Valcárcel, M. Semiconductor and carbon-based fluorescent nanodots: The need for consistency. Chem. Commun. 2016, 52, 1311-1326. [CrossRef] [PubMed]

23. Li, H.; He, X.; Kang, Z.; Huang, H.; Liu, Y.; Liu, J.; Lian, S.; Tsang, C.H.A.; Yang, X.; Lee, S.-T. Water-soluble fluorescent carbon quantum dots and photocatalyst design. Angew. Chem. Int. Ed. 2010, 49, 4430-4434. [CrossRef] [PubMed]

24. Krysmann, M.J.; Kelarakis, A.; Dallas, P.; Giannelis, E.P. Formation mechanism of carbogenic nanoparticles with dual photoluminescence emission. J. Am. Chem. Soc. 2012, 134, 747-750. [CrossRef] [PubMed]

25. Zhu, S.; Meng, Q.; Wang, L.; Zhang, J.; Song, Y.; Jin, H.; Zhang, K.; Sun, H.; Wang, H.; Yang, B. Highly photoluminescent carbon dots for multicolor patterning, sensors, and bioimaging. Angew. Chem. Int. Ed. 2013, 52, 3953-3957. [CrossRef] [PubMed]

26. Song, Y.; Zhu, S.; Xiang, S.; Zhao, X.; Zhang, J.; Zhang, H.; Fu, Y.; Yang, B. Investigation into the fluorescence quenching behaviors and applications of carbon dots. Nanoscale 2014, 6, 4676-4682. [CrossRef] [PubMed]

27. Song, Y.; Zhu, S.; Zhang, S.; Fu, Y.; Wang, L.; Zhao, X.; Yang, B. Investigation from chemical structure to photoluminescent mechanism: A type of carbon dots from the pyrolysis of citric acid and an amine. J. Mater. Chem. C 2015, 3, 5976-5984. [CrossRef]

28. Zhu, S.; Song, Y.; Zhao, X.; Shao, J.; Zhang, J.; Yang, B. The photoluminescence mechanism in carbon dots (graphene quantum dots, carbon nanodots, and polymer dots): Current state and future perspective. Nano Res. 2015, 8, 355-381. [CrossRef]

29. Wang, Y.-C.; Chuang, Y.-C.; Hsu, H.-W. The flavonoid, carotenoid and pectin content in peels of citrus cultivated in Taiwan. Food Chem. 2008, 106, 277-284. [CrossRef]

30. Fernández, P.; González, M.; Regenjo, M.; Ares, A.M.; Fernández, A.M.; Lorenzo, R.A.; Carro, A.M. Analysis of drugs of abuse in human plasma using microextraction by packed sorbents and ultra-high-performance liquid chromatography. J. Chromato. A 2017, 1485, 8-19. [CrossRef] [PubMed]

(C) 2018 by the authors. Licensee MDPI, Basel, Switzerland. This article is an open access article distributed under the terms and conditions of the Creative Commons Attribution (CC BY) license (http:// creativecommons.org/licenses/by/4.0/). 